J. Lake Sci. (湖泊科学), 2011, 23(3):339-347

http: //www.jlakes.org. E-mail: jlakes@niglas.ac.cn

(C) 2011 by Journal of Lake Sciences

\title{
太湖水质时空特性及其与蓝藻水华的关系 *
}

\author{
张晓晴,陈求稳** \\ (中国科学院生态环境研究中心, 北京 100085 )
}

\begin{abstract}
摘 要: 以太湖 2005-2007 年的连续监测资料为基础,运用聚类分析和自相关分析方法,针对总无机磷、总无机氮、水温 等环境理化因素与叶绿素 a 进行时空序列分析,初步归纳了当前太湖水质指标变化的空间特点、时间周期性及其与蓝藻 水华暴发的关系. 结果表明,太湖水质的空间分布大致分为三个人湖河口、四个湖湾、湖心区、西部湖区、东部湖区等十个 区, 其中入湖河口和北部湾区富营养化明显高于其他区, 人湖河口的氮磷含量高于北部湾区, 外源污染是造成水质恶化 的根本原因. 叶绿素 $\mathrm{a}$ 与总无机氮、铵态氮、水温呈显著相关关系, 月平均指标显示水华暴发期集中在 4-10月份, 其中梅 梁湾、贡湖和竺山湾为水华暴发的高发区,呈多峰形态.
\end{abstract}

关键词: 太湖;富营养化;水华;水质;叶绿素 a

\section{Spatial-temporal characteristic of water quality in Lake Taihu and its relationship with algal bloom}

\section{ZHANG Xiaoqing \& CHEN Qiuwen}

( Research Center for Eco-Environmental Sciences, Chinese Academy of Sciences, Beijing 100085, P. R. China)

\begin{abstract}
Based on continuous monitoring data from 2005 to 2007 in Lake Taihu, spatial and temporal series were analyzed using cluster analysis and self-correlation method for chlorophyll-a and total inorganic phosphorus, total inorganic nitrogen, water temperature and other physical and chemical factors of the aquatic environment. The current spatial-temporal characteristics of water quality in Lake Taihu and their relationship with algal bloom are summarized. The results revealed that the spatial distribution of water quality roughly divided into ten groups, including three estuaries, four bays, center lake, western area and eastern area. The degree of eutrophication in estuaries and the northern bays was significantly higher than other areas, while nitrogen and phosphorus in estuaries were higher than those in northern bays because of external source pollution. A significant correlation between chlorophyll-a and total inorganic nitrogen, ammonia nitrogen, water temperature was noted. The monthly average chlorophyll-a displayed that algal bloom occurred mainly from April to October and Meiliang Bay, Gonghu Bay, Zhushan Bay had high coincidence, showing multiple peaks.
\end{abstract}

Keywords: Lake Taihu; eutrophication; algal bloom; water quality ; chlorophyll-a

湖泊富营养化形成机制及其与水华的关系是目前国际研究热点之一 ${ }^{[1-2]}$.太湖作为我国著名的淡水湖 泊,位于经济发展较快的长江下游三角洲地区,该地区人口密度大,城市化程度高. 太湖富营养化从 1980s 开 始, 每隔 10 年上升一个等级, 而水质则下降一个等级 ${ }^{[3]}$. 目前全湖处于富营养到重富营养状态 , 水质属于劣 $\mathrm{V}$ 类. 太湖是上海、苏州、无锡等大中城市的水源地，近年来水华加剧引起了多方面的重视. 太湖拥有人湖河 流 200 多条 ${ }^{[4-5]}$, 富营养化呈现空间异质性. 因此亟需认知太湖的水质特性来掌握富营养化和水华的关系.

近年来, 陈宇炜等 ${ }^{[6]}$ 以长序列资料为基础, 运用多元逐步回归统计方法, 分析了环境因子与藻类生物量 的关系, 预测了藻类生物量的变化; 许梅等 ${ }^{[7]}$ 分析太湖人湖河道水体氮磷等指标的年变化、各水质指标及其 与降雨量、温度等生态因子的相关性,但在研究方法上是对局部区域进行多指标综合相关分析, 缺少以太湖 整体空间划分为基础的水质和藻类分析. 所以本文在前人研究基础上,利用整个太湖湖区的长期监测资料,

* 国家自然科学基金项目 (50910022) 和中国科学院知识创新工程项目 (KZCX1 - YW - 14) 联合资助. 2010 - 05-24 收稿;2010-09-06 收修改稿. 张晓晴,女, 1982 年生, 博士研究生;E-mail : qingfan006@ yahoo. cn.

** 通讯作者;E-mail:qchen@ rcees. ac. cn. 
针对关键水质参数, 通过聚类分析和自相关分析, 研究太湖水质的时空特性, 讨论水质特性与蓝藻水华的关 系, 为太湖蓝藻水华预测提供理论依据.

\section{1 数据与分析方法}

\section{1 数据采集}

本研究使用的是 $2005-2007$ 年水质监测数据. 该监测网络在太湖共布设 32 个采样点 (图 1 ), 其中太湖 北部梅梁湾、贡湖湾、竺山湾、湖心区的部分点位、太湖西北的大浦口人湖区、梅梁湾西北角的直湖港人湖 区、梅梁湾东北角的梁溪河人湖区等 14 个监测站点为每月中旬监测, 而其余站点, 主要是南太湖、东太湖、 胥湖的 18 个站点则为每季度监测 1 次, 时间为 $2 、 5 、 8 、 11$ 月中旬. 监测项目包括水温 (WT)、电导率 (Cond)、 溶解氧 $(\mathrm{DO}) 、 \mathrm{pH}$ 值 $(\mathrm{pH})$ 、化学需氧量 $(\mathrm{COD})$ 、铵态氮 $\left(\mathrm{NH}_{4}^{+}-\mathrm{N}\right)$ 、硝酸盐氮 $\left(\mathrm{NO}_{3}^{-}-\mathrm{N}\right)$ 、亚硝酸盐氮 $\left(\mathrm{NO}_{2}^{-}-\mathrm{N}\right)$ 、 磷酸盐 $\left(\mathrm{PO}_{4}^{3-}\right)$ 、总磷 $(\mathrm{TP})$ 、总氮 $(\mathrm{TN})$ 及叶绿素 $\mathrm{a}(\mathrm{Chl} . \mathrm{a})$ 等. 其中 WT、Cond、DO、 $\mathrm{pH}$ 采用溶解氧测量仪 ( YSI) 现场测出; $\mathrm{COD}$ 的测定采用酸性高锰酸盐滴定法; $\mathrm{NH}_{4}^{+}-\mathrm{N}$ 的测定采用纳氏试剂分光光度法; $\mathrm{NO}_{3}^{-}-\mathrm{N}$ 的测定采用紫外分光光度法; $\mathrm{NO}_{2}^{-}-\mathrm{N}$ 的测定采用 1-荎基-乙二胺紫外分光光度法; $\mathrm{PO}_{4}^{3-}$ 的测定采用过硫酸钾紫外分光光度法; TP 的测定采用过硫酸钾消解一紫外分光光度法; TN 的测定采用碱性过硫酸钾消解一钼酸铵 紫外分光光度法; Chl. $\mathrm{a}$ 的测定采用丙酮提取法一紫外分光光度法 ${ }^{[8]}$. 本文主要讨论以 $W T 、 D O 、 \mathrm{NH}_{4}^{+}-\mathrm{N}$ 、总无 机磷 ( TIP, 用 $\mathrm{PO}_{4}^{3-}$ 的值表示) 、总无机氮 ( TIN, 为 $\mathrm{NH}_{4}^{+}-\mathrm{N} 、 \mathrm{NO}_{3}^{-}-\mathrm{N} 、 \mathrm{NO}_{2}^{-}-\mathrm{N}$ 之和)、Chl. a 为代表的太湖水质特 性及其与蓝藻水华的关系.

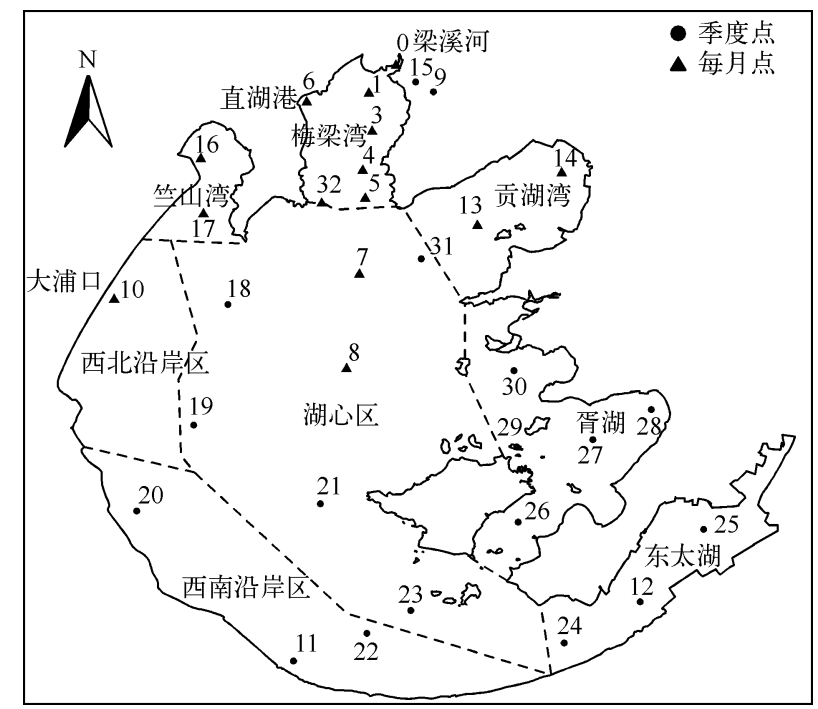

图 1 根据富营养化程度划分的太湖功能图及水质调查监测站点

Fig. 1 Function diagram according to eutrophication divided in Lake Taihu and sampling stations for water quality investigation

\section{2 分析方法}

研究中采用自相关分析方法进行时间序列分析,采用变量聚类分析进行空间动态分析.

时间自相关分析可用于时间序列检验和模型识别, 通常以自相关函数 (Auto-correlation Function, ACF) 表示, 并给出相应的自相关图 ${ }^{[9-10]}$. 自相关表示某个序列与其自身经过某些阶数滞后形成的序列之间存在某 种程度的相关性, 当两者之间存在显著相关性时, 该序列的当前状态可由序列过去的变化进行解释; 由于序 列与其某阶滞后序列的相关性可能影响到它与其他阶数滞后序列的相关性, 故需要剔除前者的影响. 自相 关函数为: 


$$
R(k)=\frac{E\left[\left(X_{i}-\mu_{i}\right)\left(X_{i+k}-\mu_{i+k}\right)\right]}{\sigma^{2}}
$$

式中, $E$ 为期望值; $X_{i}$ 为在 $t(i)$ 时的随机变量值; $\mu_{i}$ 为在 $t(i)$ 时的预期值; $X_{i+k}$ 为在 $t(i+k)$ 时的随机变量值; $\mu_{i+k}$ 为在 $t(i+k)$ 时的预期值; $\sigma^{2}$ 为方差. 所得的自相关值 $R$ 的取值范围为 $[-1,1], 1$ 为最大正相关值, -1 则为最大负相关值.

变量聚类分析是将几个样本各自成一类,然后规定类与类之间的距离,距离最小的两类合并成一个新 类, 计算新类与其他类的距离, 再将距离最小的两类进行合并, 这样每次减少一类, 直到所有的样本都归为 一类为止, 常用欧氏距离度量样本之间的距离 ${ }^{[11]}$.

\section{2 结果与分析}

水华的直接标志是藻类的急剧增殖. 湖泊水华是多种藻类的混合体, 发生水华水体中 Chl. a 浓度一定比 未发生水华水体中 Chl. a 浓度高. 由于 Chl. a 在藻类物质中占的比例相对稳定 ${ }^{[12-13]}$, 因此本研究以 Chl. a 为 指标来表征水华发生 (1).

\section{1 水质的空间特性及其与水华的关系}

为了研究水质的空间特征,采用聚类分析法对不同监测站控制水域的水质指标(包括 WT、DO、COD、 $\mathrm{NH}_{4}^{+}-\mathrm{N} 、 \mathrm{TP} 、 \mathrm{TN}$ 及 Chl. a) 进行分析. 在聚类之前, 先进行数据标准化.

根据各个监测站点监测指标的相似性, 可将 32 个监测站点分为十组 (图 2$)$. 第一组位于梁溪河口 $\left(0^{\#}\right)$; 第二组位于直湖港 $\left(6^{\#}\right)$; 第三组位于大浦口 $\left(10^{\#}\right)$; 第四组位于梅梁湾 $\left(1^{\#} 、 3^{\#} 、 4^{\#} 、 5^{\#} 、 32^{\#}\right)$; 第五组位于五里 湖 $\left(9^{\#} 、 15^{\#}\right)$; 第六组位于竺山湾 $\left(16^{\#} 、 17^{\#}\right)$; 第七组位于贡湖湾 $\left(13^{\#} 、 14^{\#}\right)$; 第八组大部分位于西部湖区 $\left(11^{\# 、}\right.$ $\left.12^{\#} 、 20^{\#}-23^{\#} 、 31^{\#}\right)$; 第九组位于东部湖区 $\left(24^{\#}-30^{\#}\right)$; 第十组位于湖心区 $\left(7^{\#} 、 8^{\#} 、 18^{\#} 、 19^{\#}\right)$, 基本反映了太湖 的富营养化空间状况 (图 1).

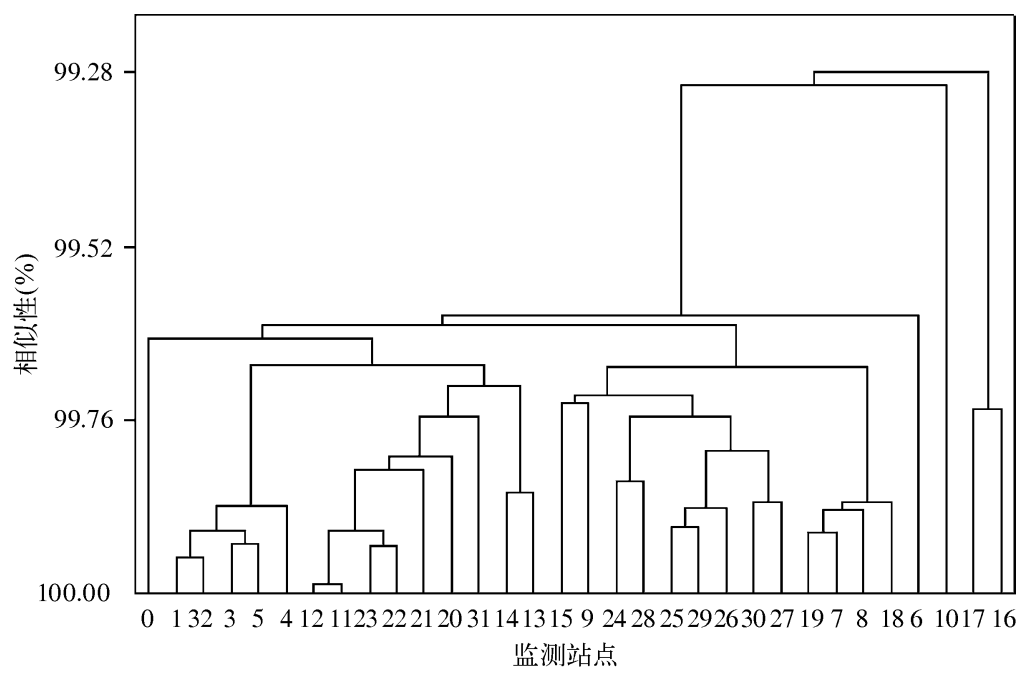

图 2 太湖监测站点聚类图

Fig. 2 Cluster figure for sampling stations in Lake Taihu

(1) 蓝藻水华发生最感官的指标是水面出现大片颗粒状或带状蓝藻. 水华发生的直接标志是藻类的急剧增殖, 由于 Chl. a 在藻类中所占比例相对稳定, 所以本研究以 Chl. a 为指标来表征水华发生, 即以 Chl. a 的周期来表征水华周期. Chl. $\mathrm{a}$ 浓度、藻类生物量和藻细胞浓度从某种程度上都可以表征水华, 水利部只颁发了藻细胞浓度水华发生的临界值, 为 $10^{8}$ cells/L. 
太湖北部梅梁湾有主要人湖口梁溪河和直湖港, 来水流域多为平原和城镇地区, 工农业发达, 水质差; 西南部多林地, 人口密度小, 城镇少, 水质相对较好. 同时太湖的主要来水之一是南部地区的苕溪河 ${ }^{[14]}$, 主要 出水是东部的太浦河, 这样造成了南部湖区水流交换较快, 水质相对于北部较好. 由此可知, 人湖污染源是 造成太湖水质空间分布差异的最主要原因.

湖心区处于轻度富营养化而且从未进行藻类打捞, 因此其水环境特征能够比较真实地反映太湖的水质 和藻类变化情况 ${ }^{[3]} .2005-2007$ 年湖心区水体总无机磷年平均值分别为 $0.117 、 0.136 、 0.099 \mathrm{mg} / \mathrm{L}$, 总无机 氮分别为 $3.111 、 3.042 、 2.789 \mathrm{mg} / \mathrm{L}, \mathrm{Chl} . \mathrm{a}$ 分别为 $10.870 、 10.079 、 20.993 \mu \mathrm{g} / \mathrm{L}$ ( 图 3 ). 从监测平均值看, 水 体 TIP 和 TIN 的浓度没有根本改变, Chl. a 含量也不断增高, 太湖富营养化没有得到根本控制, 发生水华的 危险性仍旧很高.
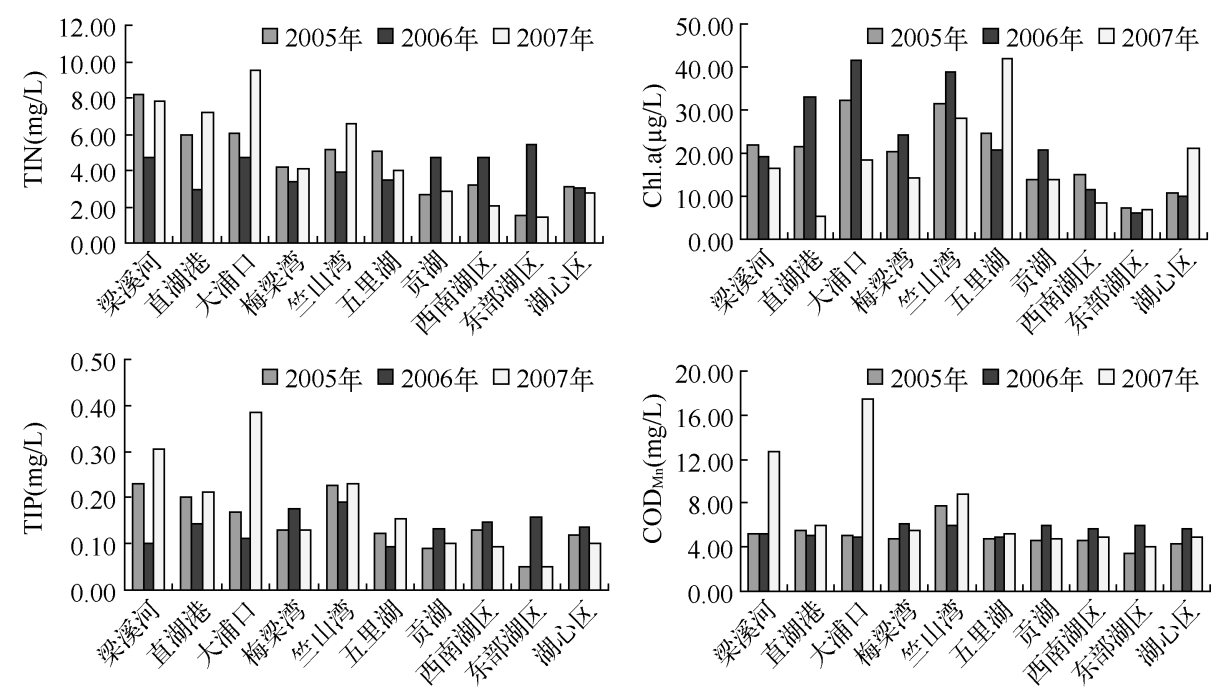

图 3 不同湖区水质指标年平均值 $(2005-2007$ 年)

Fig. 3 Annual average of water quality in different areas during 2005-2007

大浦口和竺山湾 Chl. a 浓度相对较高, 3 年平均值分别为 $30.756 \mu \mathrm{g} / \mathrm{L}$ 和 $32.906 \mu \mathrm{g} / \mathrm{L}$, 其次为梅梁湾、 五里湖和梁溪河, 而东部湖区、西南湖区和湖心区的年平均值仅分别为 $6.787 、 11.569 、 13.980 \mu \mathrm{g} / \mathrm{L}$. 另外虽 然 2007 年水华特别严重, 但是贡湖 2007 年的 Chl. a 浓度反而不高, 仅为 $16.227 \mu \mathrm{g} / \mathrm{L}$, 这与 2007 年 5 月发生 贡湖水厂饮用水危机后“引江济太” ${ }^{[15]}$ 调水有很大关系.

TIP 和 TIN 则表现出更大的空间差异性. 梁溪河、直湖港、大浦口和竺山湾明显高于其他地区, 其中梁溪 河的 TIN 、TIP 的平均值分别为 $6.892 、 0.213 \mathrm{mg} / \mathrm{L}$, 直湖港为 $5.379 、 0.185 \mathrm{mg} / \mathrm{L}$, 大浦口为 $6.758 、 0.222 \mathrm{mg} / \mathrm{L}$, 竺山湾为 $5.219 、 0.216 \mathrm{mg} / \mathrm{L}$, 而东部湖区仅为 $2.772 、 0.086 \mathrm{mg} / \mathrm{L}$, 湖心区为 $2.981 、 0.118 \mathrm{mg} / \mathrm{L}$, 仅为人湖口 的 $1 / 3$. 可见水华频繁发生的北部区域,富营养化也较严重.

$\mathrm{COD}_{\mathrm{Mn}}$ 也表现出人湖口值较高的规律. $\mathrm{COD}_{\mathrm{Mn}}$ 最高的是梁溪河、直湖港、大浦口和竺山湾, 年平均值分别 为 $7.754 、 5.498 、 9.141 、 7.501 \mathrm{mg} / \mathrm{L}$, 而湖心区年平均值为 $4.952 \mathrm{mg} / \mathrm{L}$, 说明外源污染是影响太湖 $\mathrm{COD}_{\mathrm{Mn}}$ 的重 要原因. 其中 2007 年人湖口的 $\mathrm{COD}_{\mathrm{Mn}}$ 年平均值明显高于前两年, 这与 2007 年水华特别严重有关.

\section{2 水质的时间特性及其与水华的关系}

藻类在受水质、气象、水文等外界条件的影响下, 在条件适宜时期, 出现暴发 $\rightarrow$ 死亡 $\rightarrow$ 暴发 $\rightarrow$ 死 亡 $\rightarrow \cdots \cdots$. 等多个周期,一般在每年的 4-10 月达到水华发生危险期 (图 4), 呈现不同的高峰 ${ }^{[16]}$. 选择 $2005-$ 2007 年梅梁湾、贡湖、竺山湾和人湖口的 Chl. a 月平均值进行时间序列分析, 结果表明梅梁湾 Chl. a 原始序 列与滞后 4 阶后构成的序列的自相关系数最大,为 0.293 , 且在置信区间内, 自相关不显著. 对照图 5 发现, 梅梁湾 2005 年 4-10 月份 Chl. a 浓度呈现单峰形态,2006 年和 2007 年呈现三峰形态, 无显著自相关性. 梅 
梁湾的主要入湖污染来自直湖港和梁溪河, 由于其独特的地理位置和富营养化最严重, 太湖藻类水华的发 生一般出现在稳定大风作用过后的小风或静风、天气晴朗时段, 5-10月份风向多为东南风 ${ }^{[17]}$, 导致局部藻 类聚集, Chl. a 浓度较高; 但是由于风浪的不稳定性和太湖富营养化的日益加重, 导致 Chl. a 的周期性降低.
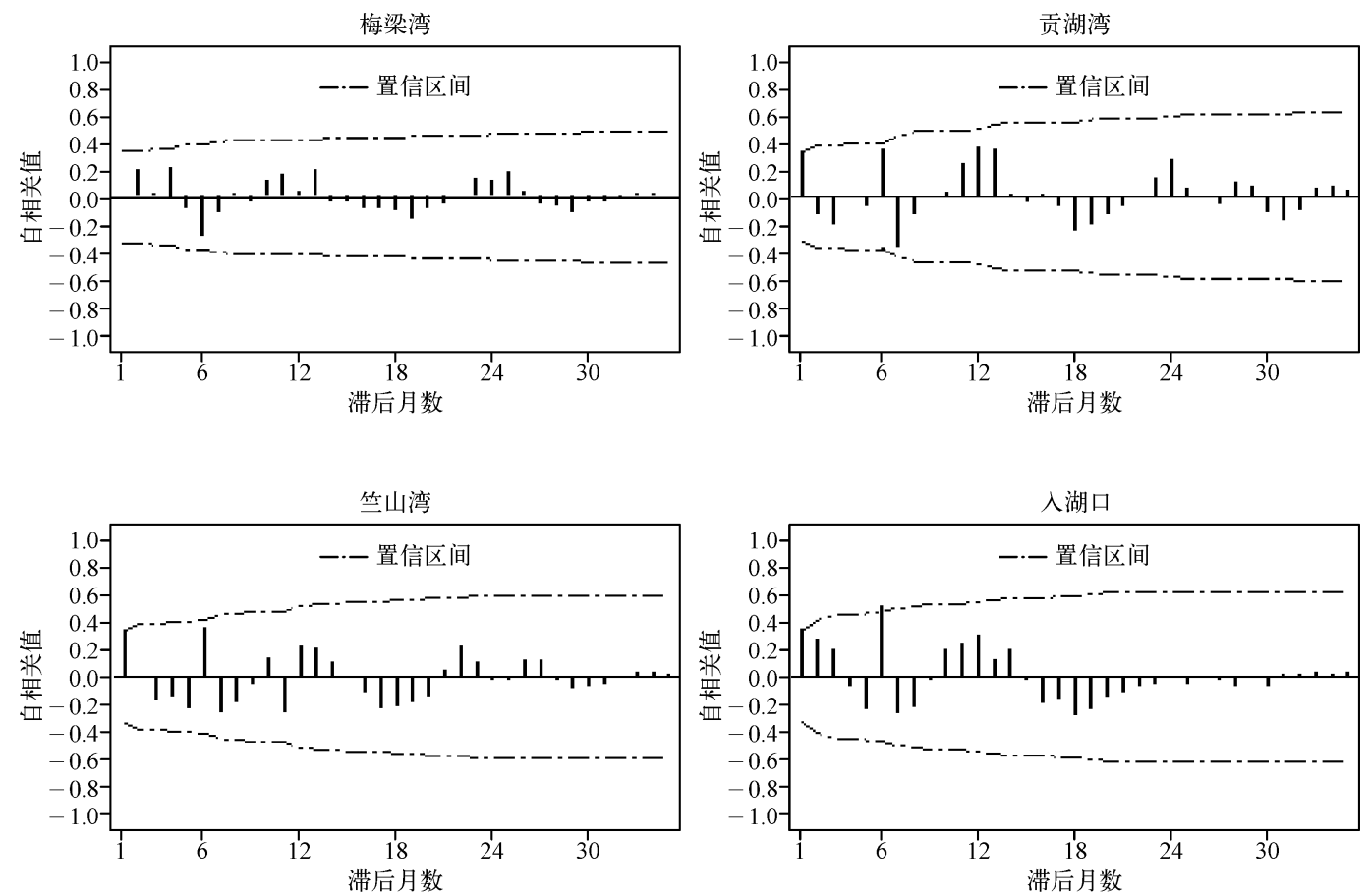

图 4 典型湖区 Chl. a 的自相关图

Fig. 4 Auto-correlation of Chl. a in typical areas

贡湖 Chl. a 原始序列滞后一阶的自相关系数为 0.378 ,超过置信区间, 自相关显著; 原始序列与滞后 6 阶 后构成的序列自相关系数最大, 为 0.386 . 对照图 5 发现, 贡湖湾 2005-2007 年 4、5 月份和 9、10 月份Chl. a 浓度每年呈现两个高峰, 周期为 6 个月, 自相关显著. 贡湖湾富营养化程度和 Chl. a 浓度相对梅梁湾和竺山 湾较低,在 2007 年突发贡湖水厂饮用水危机之前,贡湖湾水质较稳定,因此 Chl. a 浓度呈现周期性.

竺山湾 Chl. a 原始序列滞后一阶的自相关系数为 0.378 , 超过置信区间, 自相关显著; 原始序列与滞后 6 阶后构成的序列的自相关系数最大,为 0.404 . 对照图 5 发现,竺山湾 2005-2007 年 4、5 月份和 9、10月份 Chl. a 浓度每年呈现两个高峰, 周期为 6 个月, 自相关显著. 竺山湾毗邻梅梁湾, 富营养化程度较高, 水质稳 定, Chl. a 浓度周期性较强.

人湖口 Chl. a 原始序列滞后一阶的自相关系数为 0.378 ,超过置信区间, 自相关显著. 原始序列与滞后 6 阶后构成的序列的自相关系数最大, 为 0.487 . 对照图 5 发现, 人湖口 $2005-2007$ 年 $4 、 5$ 月份和 $9 、 10$ 月份 Chl. a 浓度每年呈现两个高峰,周期为 6 个月,自相关显著. 梁溪河、直湖港和大浦口作为太湖三个主要人湖 口, 外源污染严重, 营养盐程度很高, 只有梅梁湾的 TN、TP 在夏季偶尔高出人湖口. 由于夏季风向多为东南 风, 人湖口的藻类在夏季 6-9 月堆积聚集, Chl. a 浓度较高.

选择 2005-2007 年 4-10 月份梅梁湾、贡湖湾、竺山湾与人湖口的 Chl. a 和 DO、WT、DIP、DIN、 $\mathrm{NH}_{4}^{+}-\mathrm{N}$ 、 $\mathrm{NO}_{3}^{-}-\mathrm{N}$ 的月平均值进行相关性分析 (表 1 , 表 2).

在水华生长旺季, 北部富营养化较严重的梅梁湾、贡湖湾、竺山湾和人湖口等区域 Chl. a 均与水质指标 TIN $、 \mathrm{NH}_{4}^{+}-\mathrm{N}$ 呈显著负相关, 这说明富营养化很大程度上受制于营养盐的累积程度, 蓝藻水华与富营养化的程 度是密不可分的, 在水华发生发展时, 大量的氮被吸收利用. 但是 Chl. a 和 $\mathrm{NH}_{4}^{+}-\mathrm{N}$ 的相关性高于 $\mathrm{TIN}\left(\mathrm{NH}_{4}^{+}-\mathrm{N}\right.$ 

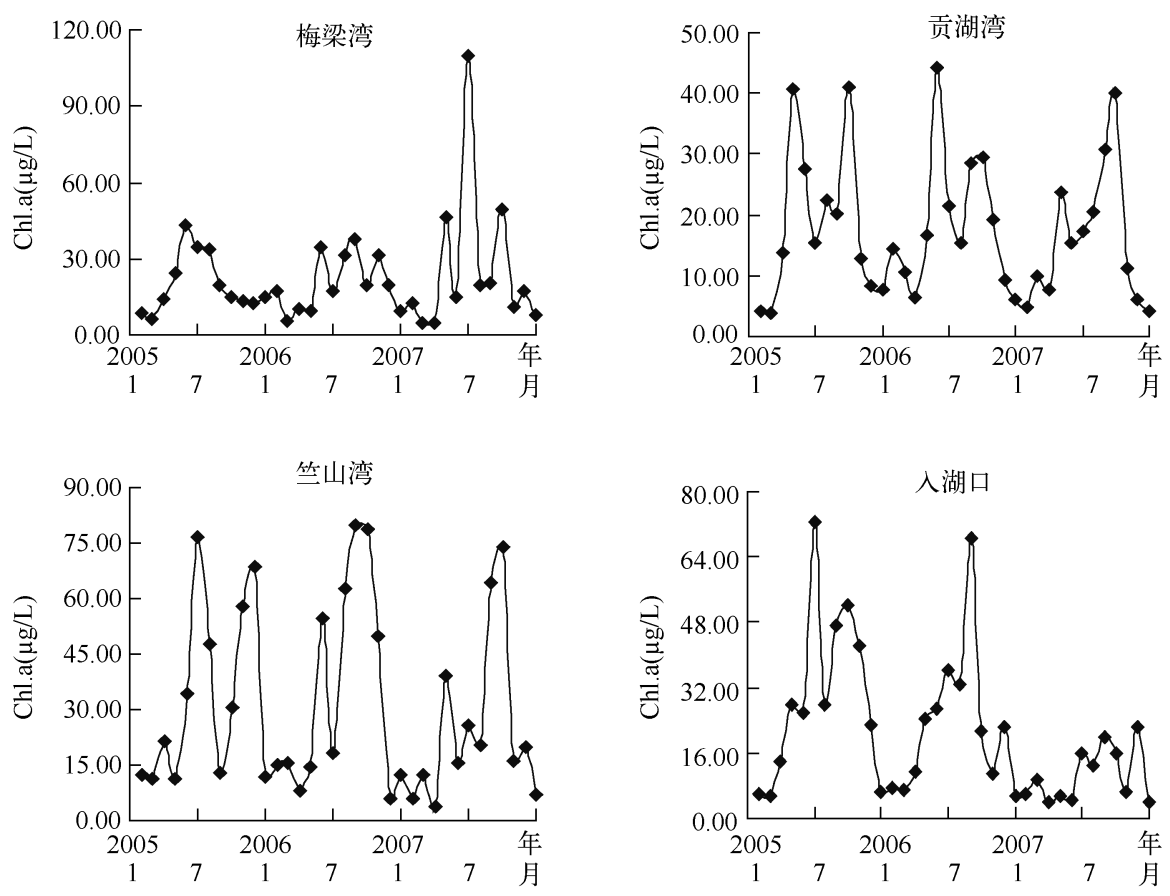

图 5 2005-2007 年典型湖区 Chl. a 的时间变化

Fig. 5 Changes of Chl. a in typical areas from 2005 to 2007

表 1 梅梁湾、贡湖湾、竺山湾 Chl. a 与水质指标的相关关系*

Tab. 1 Correlation between Chl. a and water quality in Meiliang Bay, Gonghu Bay, Zhushan Bay

\begin{tabular}{cccccccc}
\hline & Chl. a & DO & WT & TIN & TIP & $\mathrm{NH}_{4}^{+}-\mathrm{N}$ & $\mathrm{NO}_{3}^{-}-\mathrm{N}$ \\
\hline Chl. a & 1.00 & & & & & & \\
DO & $-0.865^{* *}$ & 1.00 & & & & & \\
WT & $0.858^{* *}$ & $-0.78^{*}$ & 1.00 & & & & \\
TIN & $-0.763^{*}$ & $0.623^{*}$ & $-0.617^{*}$ & 1.00 & & & \\
TIP & 0.467 & -0.552 & 0.276 & -0.324 & 1.00 & 1.00 & 1.00 \\
$\mathrm{NH}_{4}^{+}-\mathrm{N}$ & -0.726 & 0.568 & $-0.768^{*}$ & $0.934^{* *}$ & -0.175 & 0.572 & -0.502 \\
$\mathrm{NO}_{3}^{-}-\mathrm{N}$ & -0.305 & 0.329 & -0.220 & $0.827^{*}$ & -0.502 & \\
\hline
\end{tabular}

*表示差异性检验泊松值 $<0.05$, 为显著相关; $* *$ 表示差异性检验泊松值 $<0.001$, 为极显著相关.

表 2 人湖口 Chl. a 与水质指标的相关关系*

Tab. 2 Correlation between Chl. a and water quality in estuaries

\begin{tabular}{cccccccc}
\hline & Chl. a & DO & WT & TIN & TIP & $\mathrm{NH}_{4}^{+}-\mathrm{N}$ & $\mathrm{NO}_{3}^{-}-\mathrm{N}$ \\
\hline Chl. a & 1.00 & & & & & \\
DO & -0.543 & 1.00 & & & & \\
WT & 0.700 & $-0.617^{*}$ & 1.00 & & & \\
TIN & $-0.677^{*}$ & 0.090 & $-0.530^{*}$ & 1.00 & & \\
TIP & 0.064 & 0.111 & 0.219 & -0.057 & 1.00 & & \\
$\mathrm{NH}_{4}^{+}-\mathrm{N}$ & $-0.708^{*}$ & 0.102 & $-0.597^{*}$ & $0.991^{* *}$ & 0.003 & 1.00 & 1.00 \\
$\mathrm{NO}_{3}^{-}-\mathrm{N}$ & $-0.502^{*}$ & 0.127 & -0.232 & $0.847^{*}$ & -0.286 & $0.769^{*}$ & 1.00 \\
\hline
\end{tabular}

$*$ 表示差异性检验泊松值 $<0.05$, 为显著相关; $* *$ 表示差异性检验泊松值 $<0.001$, 为极显著相关. 
在 TIN 中占的比例大于 $70 \%$ ), 由于藻类在利用氮源合成氨基酸时硝酸盐必须先转换成铵,一般认为藻类倾 向于优先利用铵态氮, 它是藻类吸收的直接形式, 所以 Chl. a 和 $\mathrm{NH}_{4}^{+}-\mathrm{N}$ 呈显著正相关. 而 Chl. a 与 TIP 的相 关性不显著, TIP 的减少相对于 Chl. a 的增加具有一定的滞后性 (图 6, 图 7). 藻类对磷的吸收利用不仅与磷 的化学形态有关, 也与水体中磷的溶解状态有关. 在武汉东湖的水体中探讨了总溶解磷、溶解反应磷、总反 应磷、溶解水解磷以及颗粒磷对小球藻生长的生物有效利用性 ${ }^{[18]}$, 结果表明虽然只有溶解反应磷能够 $100 \%$ 被小球藻利用, 其他各种溶解状态的磷均含有生物无法吸收利用的一部分 (溶解水解磷的利用率为 84\% ). 可见 Chl. a 含量也是与各种形态磷之间的相互作用有关. 因此就溶解状态而言, 虽然藻类直接吸收的 是水溶磷, 但水溶磷含量与藻类生长量并没有显著的相关性, 也可以说藻类的生长是与各种不同形态的磷 之间相互作用有关.

冬春季节氮的含量较高 ${ }^{[19-22]}$, 人湖口的 TIN 平均值为 $4.915 \mathrm{mg} / \mathrm{L}$, 梅梁湾、贡湖、竺山湾的 TIN 平均值为 $3.030 \mathrm{mg} / \mathrm{L}$ (图 6 , 图 7), 说明太湖的氮污染主要来自于外源污染, 三个湖湾毗邻人湖口, 富营养化严重.

Chl. a 与 WT 呈显著正相关, 表明 Chl. a 浓度主要受年内季节变化的影响. 太湖位于亚热带地区,具有盛 夏炎热、隆冬寒冷的特征, 水温四季变化分明, 每年的 5 月初至 10 月中旬太湖表面水温较高, 达到 $20^{\circ} \mathrm{C}$ 以 上. 水华大多发生在春初到秋初, 此时随着温度的升高, 促进了蓝藻优势种微囊藻的生长, 使其在一定温度 下上浮聚集 ${ }^{[23]}$, 为蓝藻水华暴发创造了条件.
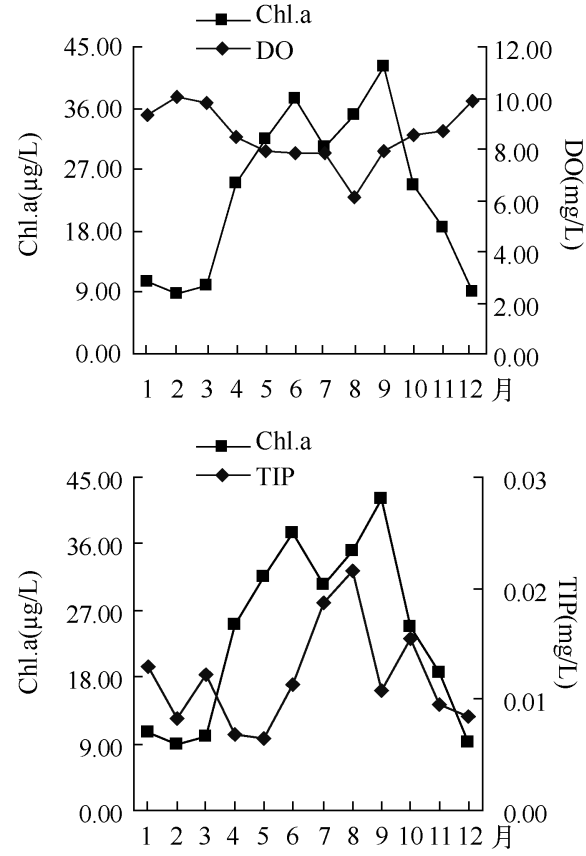
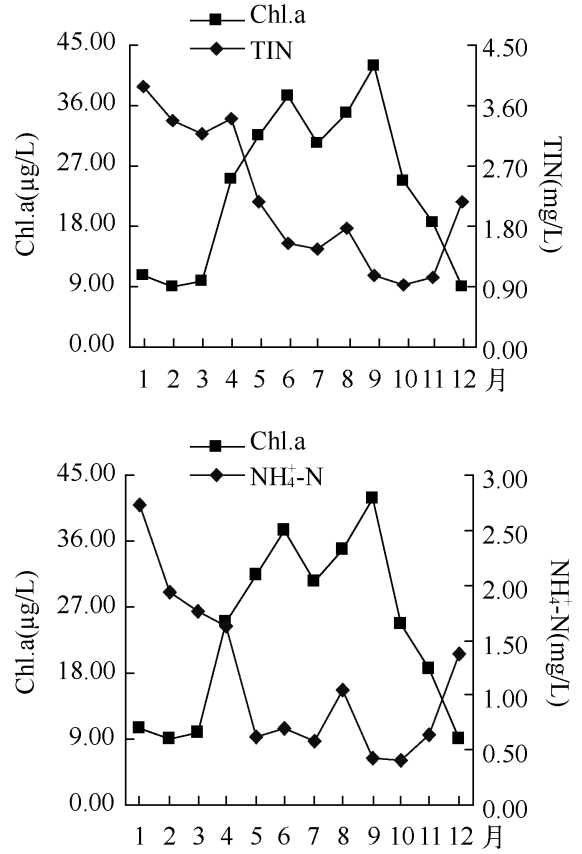

图 6 梅梁湾、贡湖、竺山湾 Chl. a 与水质指标的关系

Fig. 6 Relationship between Chl. a and water quality in Meiliang Bay, Gonghu Bay, Zhushan Bay

\section{3 结论}

(1) 太湖水质呈现较大的空间差异性,主要表现为北部梅梁湾、贡湖和䇥山湾富营养化较严重,也是蓝 藻水华的高发区; 而湖心区和东部湖区富营养化相对较轻. 湖心区 2005-2007 年的水质变化趋势显示, 太湖 富营养化没有得到根本控制.

(2) 太湖蓝藻水华已进人了高频期. 2005-2007 年太湖蓝藻水华发生呈多峰形状态.

（3）相关性分析表明,冬春之季,太湖湖体氮磷量均处于较高水平,使藻类生长有了很大的潜力, 为后 期蓝藻水华的大规模发生奠定了基础,具备了快速生长的内部环境; 其次高温天气对蓝藻水华发生起到诱 

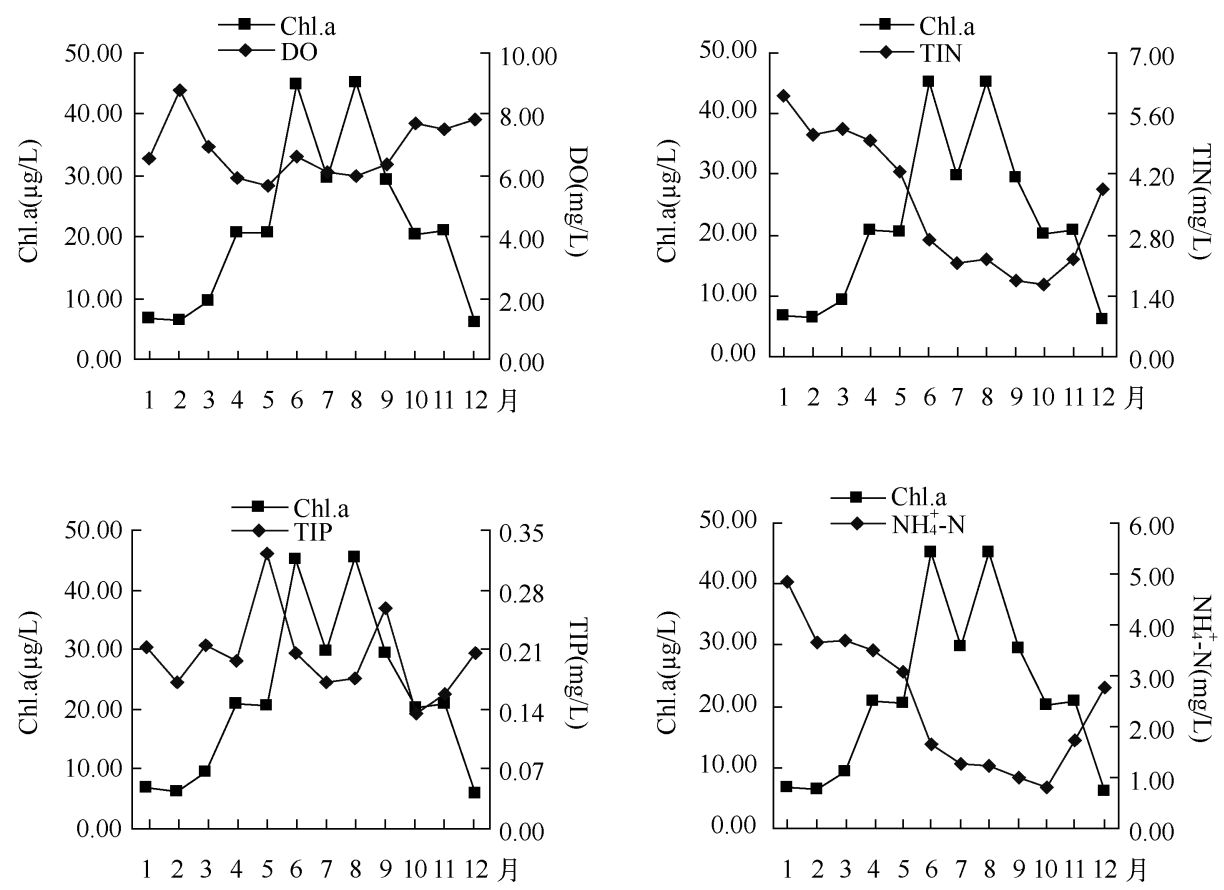

图 7 人湖口 Chl. a 与水质指标的关系

Fig. 7 Relationship between Chl. a and water quality in estuary

导作用. 由于太湖的营养状态在变化之中, 因而诱发蓝藻水华发生的温度条件也在不断变化.

\section{4 参考文献}

[ 1 ] Chen YW, Qin BQ, Teunner K et al. Long-term dynamics of phytoplankton assemblages: Microcystis-domination in Lake Taihu, a large shallow lake in China. Journal of Plankton Research, 2003,25 (1) :445-453.

[ 2 ] 朱广伟. 太湖富营养化现状及原因分析. 湖泊科学,2008,20(1):21-26.

[ 3 ] 秦伯强, 王小冬, 汤祥明. 太湖富营养化与蓝藻水华引起的饮用水危机一一原因与对策. 地球科学进展, 2007,22 (9) :897-898.

[ 4 ] 高锡云, 陈宇炜, 蔡后建. 梅梁湾及大太湖水环境现状与富营养化趋势分析. 见: 蔡启铭编. 太湖环境生态研究 (一). 北京:气象出版社,1998:323-337.

[ 5 ] 陈宇炜, 高锡云. 西太湖北部微囊藻时空分布及其与光温等环境因子关系的研究. 见: 蔡启铭编. 太湖环境生态研 究 (一). 北京:气象出版社, $1998: 268-280$.

[ 6 ] 陈宇炜, 秦伯强, 高锡云. 太湖梅梁湾藻类及相关环境因子逐步回归统计和蓝藻水华的初步预测. 湖泊科学, 2001, 13 (1):64-71.

[ 7 ] 许 梅,任瑞丽, 刘茂松. 太湖人湖河流水质指标的年变化规律. 南京林业大学学报 (自然科学版),2007,31 (6): 121-124.

[ 8 ] 国家环境保护局《水和废水监测分析方法》编委会. 水和废水监测分析方法 (第四版). 北京: 中国环境科学出版 社,1997.

[ 9 ] 杨叔子,吴 雅,轩建平. 时间序列分析工程应用. 武汉:华中理工大学出版社, 1992:258.

[10] 李力春. 自相关函数在时间序列分析中的应用. 上海: 上海统计出版社,2001:35.

[11] 黄钰玲. 三峡水库香溪河库湾水华生消机理研究 [学位论文]. 西安:西北农林科技大学,2007.

[12] 刘建萍, 张玉超, 钱 新等. 太湖蓝藻水华的遥感监测研究. 环境污染与防治, 2009,31(8): 79-83.

[13］张宁红, 黎 刚, 郁建桥等. 太湖蓝藻水华暴发主要特征初析. 中国环境监测, 2009,25(1):71-73.

[14] 朱广伟, 高 光, 秦伯强等. 浅水湖泊沉积物中磷的地球化学特征. 水科学进展, 2003,14(6):715-719. 
[15] 王志红,崔福义,安 金.氮磷与“藻华”生物量预测的模型探讨. 哈尔滨工业大学学报,2006,38(5):740-743.

[16] 王苏民,窦鸿身. 中国湖泊志. 北京:科学出版社,1998:3-21.

[17] 范成新,陈宇炜, 吴庆龙等. 夏季盛行风对太湖北部藻类水华分布的影响. 上海环境科学, 1998,17(8):258-270.

[18] 陈 琼. 氮磷对水华发生的影响. 生物学通报,2006,41(5):12-15.

[19］李恒鹏,杨桂山,黄文钰等. 太湖上游地区面源污染氮素人湖量模拟研究. 土壤学报,2007,44(6):1063-1069.

[10] Townsend SA, McCarthy MJ, Brandes JA. Stable isotopic composition of nitrate in Lake Taihu, China and major inflow rivers. Hydrobiologia, $2007, \mathbf{5 8 1}$ ( 1 ) :135-140.

[21] 杨龙元, 秦伯强, 胡维平等. 太湖大气氮、磷营养元素干湿沉降率研究. 海洋与湖沼, 2007,38(2):104-110.

[22] 宋玉芝,秦伯强, 杨龙元等. 大气湿沉降向太湖水生生态系统输送氮的初步估算. 湖泊科学, 2005,17(3):226-230.

[23] 华锦彪,宗志祥. 洋河水库“水华”发生的实验研究. 北京大学学报(自然科学版), 1994,30(4):476-483. 